\title{
BMJ Global Health The distributional impact of taxing sugar-sweetened beverages: findings from an extended cost-effectiveness analysis in South Africa
}

\author{
Akshar Saxena, ${ }^{\oplus 1,2}$ Nicholas Stacey, ${ }^{\oplus 3}$ Paula Del Ray Puech, ${ }^{2}$ Caroline Mudara, ${ }^{3}$ \\ Karen Hofman, ${ }^{3}$ Stéphane Verguet ${ }^{\odot 2}$
}

To cite: Saxena A, Stacey N, Puech PDR, et al. The distributional impact of taxing sugar-sweetened beverages: findings from an extended cost-effectiveness analysis in South Africa. BMJ Global Health 2019;4:e001317. doi:10.1136/ bmjgh-2018-001317

Handling editor Sanni Yaya

- Additional material is published online only. To view please visit the journal online (http://dx.doi.org/10.1136/ bmjgh-2018-001317).

Received 19 November 2018 Revised 27 May 2019 Accepted 28 May 2019

Check for updates

(c) Author(s) (or their employer(s)) 2019. Re-use permitted under CC BY-NC. No commercial re-use. See rights and permissions. Published by BMJ.

${ }^{1}$ Economics, Nanyang Technological University, Singapore, Singapore ${ }^{2}$ Department of Global Health and Population, Harvard T.H. Chan School of Public Health, Boston, Massachusetts, USA ${ }^{3}$ SAMRC/Wits Center for Health Economics and Decision Science - PRICELESS SA School of Public Health Faculty of Health Sciences, University of the Witwatersrand, Johannesburg, South Africa

Correspondence to Stéphane Verguet; verguet@hsph.harvard.edu

\section{ABSTRACT}

Background Facing increasing obesity prevalence and obesity-related disease burden, South Africa has devised an obesity prevention strategy that includes a recently implemented tax on the sugar content of sugar-sweetened beverages (SSB). We assess the potential distributional impact (across socioeconomic groups) of this tax on type 2 diabetes mellitus (T2DM) incidence and associated mortality and its financial burden on households. Methods We conducted an extended cost-effectiveness analysis of the new $10 \%$ tax on SSBs in South Africa, and estimated: the averted premature deaths related to T2DM, the financial benefits to households (out-of-pocket (OOP) medical costs and indirect costs due to productivity losses averted), the increased government tax revenues and healthcare savings for the government, all across income quintiles.

Findings A $10 \%$ SSB tax increase would avert an estimated 8000 T2DM-related premature deaths over 20 years, with most deaths averted among the third and fourth income quintiles. The government would save about South African rand (ZAR) 2 billion (US $\$ 140$ million) in subsidised healthcare over 20 years; and would raise ZAR6 billion (US\$450 million) in tax revenues per annum. The bottom two quintiles would bear the smallest tax burden increase (36\% of the additional taxes). The bottom two income quintiles would also have the lowest savings in 00P payments due to significant subsidisation provided by government healthcare. Lastly, an estimated 32000 T2DM-related cases of catastrophic expenditures and 12000 cases of poverty would be averted.

Conclusions SSB taxation would have a substantial distributional impact on obesity-related premature deaths, cost savings to the government and the financial outcomes of South Africa's population.

\section{INTRODUCTION}

In 2016, combined obesity and overweight prevalence in South Africa (SA) was $68 \%$ among women and $31 \%$ among men. ${ }^{1}$ Obesity-related non-communicable diseases (NCD) contributed to $40 \%$ of overall deaths in 2013 . ${ }^{2}$ One contributor was increased consumption

\section{Key questions}

What is already known?

- In 2018, the South African government implemented a $10 \%$ excise tax on sugar-sweetened beverages (SSB).

- Evidence from other countries suggests that a tax on SSBs is likely to reduce consumption and reduce the increasing burden of obesity-related non-communicable diseases.

What are the new findings?

- A $10 \%$ tax would avert an estimated 8000 premature deaths related to type 2 diabetes mellitus (T2DM) over 20 years, the government would save South African rand (ZAR) 2 billion in subsidised healthcare, and raise ZAR6 billion in tax revenues per annum.

- An estimated 32000 T2DM-related cases of catastrophic expenditures and 12000 cases of poverty would be averted.

- The deaths averted would be concentrated in the third and fourth income quintiles, while the bottom two income quintiles would bear the lowest burden of taxes.

What do the new findings imply?

- An SSB tax has the potential to reduce deaths due to T2DM, reduce out-of-pocket and government expenditures, and healthcare expenditure induced poverty in South Africa.

of sugar-sweetened beverages $(\mathrm{SSB}) .^{3-6}$ In 2013, SA ranked seventh in the world in sugar consumption with a per-capita annual consumption of sugar of $36 \mathrm{~kg}^{78}$ Between 2002 and 2016 annual sales of SSBs doubled from 3.0 to 6.0 billion litres. ${ }^{9}$ This increase in consumption occurred in conjunction with falling real prices, rising incomes and increasing affordability of SSBs. ${ }^{10}$

In view of the increasing burden of disease from obesity-related conditions, the SA government has implemented an excise tax 


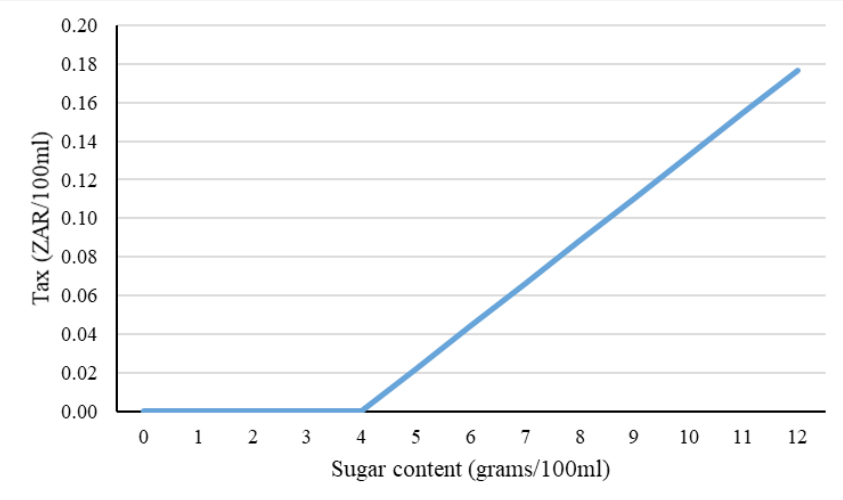

Figure 1 Tax per $100 \mathrm{~mL}$ by sugar content of taxed beverages. This figure shows the amount of tax (in ZAR/100 mL) due to sugar content in beverage (in $\mathrm{g} / 100 \mathrm{~mL}$ ). Tax is levied at 2.21 cents per $100 \mathrm{~mL}$ for each gram of sugar over a threshold of $4 \mathrm{~g} / 100 \mathrm{~mL}$. ZAR, South African rand.

on SSB as of 1 April 2018. ${ }^{11} 12$ This tax, also called the Health Promotion Levy (HPL), is levied at South African rand (ZAR) 2.21 cents for each gram of sugar over a threshold of $4 \mathrm{~g} / 100 \mathrm{~mL}$ (figure 1). Using a sugar base is relatively novel, with Mauritius and the UK being the only other jurisdictions to have done so, and has the potential to incentivise consumers to change behaviour and for producers to reduce the sugar content of their products. ${ }^{11}$ The proposed HPL amounts to an approximate $10 \%$ tax on the price of can of standard cola drink. ${ }^{11}$ The National Treasury has indicated financing of expanded health promotion programmes from a portion of additional tax revenues. ${ }^{12}$

A $10 \%-20 \%$ excise tax on SSBs, or 'soda tax', is recommended as one policy solution to the problem of increasing obesity ${ }^{1314}$ and is hypothesised to increase the retail price of SSBs and to reduce consumption accordingly. This in turn is expected to curtail a proportion of the increase in obesity and related NCDs. In 2018, twenty-seven countries including Chile, France, Mexico and Spain, and six US municipalities had implemented some form of soda tax. ${ }^{15}$ Evidence from Mexico showed that sales of taxed beverages declined by $7 \%$ per capita within the first year of tax implementation, $10 \%$ within the second year, with overall higher reductions among lower versus higher socioeconomic groups $(10 \%$ vs $6 \%){ }^{16} 17$

In response to an excise tax, manufacturers and distributers can either absorb the tax such that the retail price to the consumer does not increase after the implementation of the tax or pass a proportion of the tax to consumers resulting in an increased retail price paid at the point of sale. This is called the 'pass-through' effect to the consumers. The pass-through effect could be more than $100 \%$, that is, the retail price increases/decreases by more than the amount of the tax and is called 'overshifting', could be exactly $100 \%$ ('perfect pass-through' or 'complete shifting') or less than $100 \%$ ('undershifting'). ${ }^{18-23}$ There is evidence of overshifting of prices in responses to excise tax in Mexico (132\% increase), ${ }^{24}$ in
Denmark (300\% increase), complete shifting in France $(100 \% \text { increase })^{21}$ and undershifting in Philadelphia (61\% increase in first month and $93 \%$ increase by second month) $)^{23}$ and Berkeley, California (47\% increase in first 3 months).${ }^{19}$ Evidence from excise taxation of other products, namely beer, in SA has found similarly overshifting of tax increases to retail prices $\left(480 \%\right.$ increase).$^{25}$

Beyond the NCD challenges, SA faces a public health system that is fragile and reflects underlying economic inequalities. ${ }^{26}{ }^{27}$ These income inequalities are one of the highest globally, and arose through discriminatory government policies of the colonial and Apartheid eras which intentionally deprived all non-white citizens of meaningful access to economic opportunity through restrictions on what jobs could be held, on where residence could be taken up, on movement and through deeply skewed allocations of public resources for social services. ${ }^{28}$ The result of this deeply discriminatory past is a highly unequal distribution of income and economic well-being across which the potential differing impacts of public policies of SA's new dispensation need to be evaluated.

The introduction of the tax has not been without controversy. Opponents have argued that the tax would be regressive (ie, tax paid as proportion of income decreases as income increases) and disproportionally impact the poor. ${ }^{29} \mathrm{~A}$ systematic review found that the tax burden was regressive whereas the modelled health benefits were progressive in the USA and Australia. ${ }^{30}$ Focusing solely on the share of SSB expenditure without considering the incidence of potential health benefits and averted healthcare costs, the regressivity of taxation could be significantly overstated.

A few studies from SA have considered the effect of a potential SSB tax on consumption of SSBs, obesity prevalence and mortality due to type 2 diabetes mellitus (T2DM) ${ }^{31-36}$ Building on these previous SSB tax analyses from SA, this is the first economic modelling analysis on the potential distributional health and financial impacts among poor and rich households in SA using extended cost-effectiveness analysis (ECEA) methods. ${ }^{3738}$ Our analysis is restricted to T2DM-related mortality over a 20 -year time period instead of covering additional health conditions affected by sugar consumption in order to use these previously published studies from SA and add ECEA. Additionally, within this ECEA, we extended the analysis to savings in indirect costs due to averted productivity losses. This approach of focusing on one disease condition helps us to remain comparable to the previously published literature and extend the analysis to equity effects.

\section{METHODS}

\section{Overview}

We build on ECEA methods applied to the study of increased tobacco taxes. ${ }^{39-43}$ ECEA is a policy assessment methodology that estimates policy impact on three major 


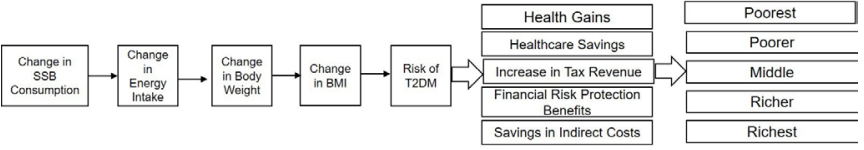

Figure 2 Conceptual pathway for modelling the health and financial impact of sugar-sweetened beverages using extended cost-effectiveness analysis. This figure shows the conceptual pathway of modelling the distribution of health and financial impact across income quintiles. Health and financial impacts are measured along five dimensions: (1) health gains as measured by change in mortality due to type 2 diabetes mellitus (T2DM); (2) healthcare savings associated with foregone treatment for T2DM; (3) increase in tax revenues; (4) financial risk protection provided by reduction in out-of-pocket (OOP) costs to households; and (5) savings in indirect costs associated with productivity losses. BMI, body mass index; SSB, sugar-sweetened beverage.

outcomes: (1) health benefits; (2) reduction of out-ofpocket (OOP) costs on health and the financial risk protection (FRP) due to reduction in OOP expenditures; and (3) the distributional impact across socioeconomic status (eg, income quintiles). ${ }^{37} 38$ Here we assess: (1) impact on SSB consumption and resulting change in body mass index (BMI); (2) subsequent change in mortality due to T2DM; (3) resultant healthcare savings associated with foregone treatment for T2DM; (4) increase in tax revenues; (5) FRP provided by reduction in OOP costs to households; (6) savings in indirect costs associated with productivity losses; and (7) distributional impact of (1-6) across income quintiles (figure 2).

In the context of SA's history of racialised discrimination, another salient dimension by which the population could have been stratified is race. While the potential differential impact of this policy on racial groups could be important, we focus our analysis on income given the concerns of regressivity in discussions of excise taxes, because the overwhelming majority of South Africans are Black Africans (about $81 \%$ ) $^{44}$ and due to lack of racially disaggregated data for SA for the variables and parameters we use in our estimation.

\section{Price, tax, elasticity and consumption of SSBs}

The policy imposes a tax of ZAR2.21 cents (US $\$ 0.18$ cents) for each gram of sugar over $4 \mathrm{~g} / 100 \mathrm{~mL} .^{12}$ As stated in a policy paper issued by the National Treasury of South Africa, a per litre price of ZAR11.45 and sugar content of $10.6 \mathrm{~g} / 100 \mathrm{~mL}$ is used to derive the total SSB tax of approximately $10 \% .{ }^{11}$ We chose a pass-through of $100 \%$ for baseline analysis to show the pure effect of price elasticity on consumption without the intervening effect of market structure that may cause overshifting (pass-through of more than 100\%) or undershifting (pass-through of less than 100\%). We quantified the change in per-capita beverage consumption using own price elasticity of demand for SSB, and pretax per-capita daily consumption by age, and income quintile (online supplementary appendix table A1). As we did not have price elasticity estimates by income quintile for $\mathrm{SA}$, we
Table 1 Price elasticity estimates of demand of sugarsweetened beverages (SSB) by income quintile for Chile, Mexico and South Africa

\begin{tabular}{llll}
\hline Income quintile & Chile & Mexico & $\begin{array}{l}\text { South } \\
\text { Africa }\end{array}$ \\
\hline Quintile 1 (lowest) & -1.49 & -1.12 & -1.26 \\
Quintile 2 & -1.55 & -1.41 & -1.20 \\
Quintile 3 & -1.26 & -1.24 & -1.20 \\
Quintile 4 & -1.29 & -1.09 & -1.14 \\
Quintile 5 (highest) & -1.29 & -0.97 & -0.98 \\
GDP per capita in & 13960 & 8450 & 5279 \\
2016 (current US\$) & & & \\
\hline
\end{tabular}

We derived the estimates for South Africa by regressing the elasticity estimates for Mexico on income quintiles for South Africa. The price elasticity estimates for Mexico are from Colchero et al and for Chile are from Guerrero-López et al. ${ }^{22} 67$ Source for GDP per capita: World Development Indicators, The World Bank (https://data.worldbank.org/indicator/NY.GDP.PCAP.CD). GDP, gross domestic product.

had to impute the income quintile-specific price elasticity. We used SSB price elasticity estimates from Mexico and used a regression approach to quantify the correlation between the quintile-specific price elasticity and income distribution. ${ }^{22}$ We then predicted the elasticity estimates by income quintile for SA (table 1). The imputed elasticity estimates are by income quintile and are constant across age and sex. The estimated median price elasticity was -1.20 which is similar to the overall price elasticity of SSB consumption from SA of $-1.18 .^{36}$

\section{Change in BMI and T2DM-related premature mortality}

A recent meta-analysis has documented the effect of SSB consumption on T2DM incidence and the included studies showed the combined effect of the various channels through which SSB consumption can affect disease incidence. ${ }^{45}$ In our study, we modelled the impact on T2DM incidence through one such channel of change in $\mathrm{BMI}$, and thus our estimates are likely to be conservative and underestimate the impact on T2DM incidence and mortality. We estimated the effect of reduced consumption on T2DM in two steps: first, the change in BMI; and second, the effect of reduced BMI on T2DM incidence and mortality.

Similar to another study, ${ }^{31}$ change in BMI was obtained in the following steps: first, the change in SSB consumption was converted into change in energy consumption using energy density of a litre of SSB; second, the change in energy consumption was converted into change in body weight using an energy balance equation; and lastly, the change in body weight was converted into change in BMI using average height. A previous study from SA calculated the energy density of SSBs to be $1800 \mathrm{~kJ} / \mathrm{L} .{ }^{32}$ Multiplying the change in SSB consumption by energy density provided the change in daily energy consumption. Energy consumption was then multiplied by the energy balance equation to obtain change in body weight. A 
previously published energy balance equation states that to obtain a $1 \mathrm{~kg}$ change in body weight for adults, a daily energy change of $94 \mathrm{~kJ}$ was required, assuming no change in physical activity. ${ }^{46}$ Having obtained the change in body weight by sex, age and income quintile, we divided it by the square of the average height in each of the respective categories to obtain the associated change in BMI. Age, sex and quintile-specific population BMI and average height were obtained from wave 4 of the National Income Dynamics Study (NIDS) survey. ${ }^{47}$

To convert changes in BMI into T2DM incidence and associated mortality and model the impact over 20 years, we used a disease incidence model..$^{31-33}{ }^{48-50}$ Using data from the Global Burden of Disease study ${ }^{51}$ on the relative risk (RR) of T2DM due to one-unit increase in BMI (table 2) and the change in age-specific BMI by quintile (calculated above), the age-specific potential impact fraction (PIF) was calculated in the model. The definition of PIF is 'the proportional reduction in incidence of a certain disease, resulting from a specific change in distribution of a risk factor in the population at risk. ${ }^{52}$ This post-tax intervention PIF was multiplied by the age-specific incidence of T2DM at baseline to obtain the post-tax incidence. The disease incidence model then conducted a simulation such that each cohort moved forward in time using the new incidence rate until they reached a maximum age of 100 years or death. This cohort-specific simulation was repeated across the income quintiles to estimate the effect on T2DM incidence and mortality over a 20-year time period.

\section{T2DM-related disease expenditures}

We calculated the reduction in OOP healthcare expenditures for households and reduction in healthcare subsidies provided by the government to the patients. To estimate treatment costs, we used cost estimates per T2DM case per year in the private sector reported by the Council of Medical Schemes, and assumed the public sector costs at approximately $70 \%$ of the private sector costs. ${ }^{31}$

The SA healthcare payment system is fairly complex and OOP payments are determined by a means-tested sliding scale in the public sector and by the presence of insurance in the private sector. Public sector patients are divided into four $\mathrm{H}$ categories by their ability to pay. $\mathrm{H} 0$ patients receive $100 \%$ subsidy, H1 70\%, H2 20\%, while H3 patients and those privately insured receive no subsidy. ${ }^{53}$ We calculated the share of the population falling into each of these subsidisation categories, and subsequently the reduction in OOP payments using the averted cases of T2DM, the potential OOP payments for the individuals in each quintile and the utilisation rates per quintile. Similarly, we estimated the reduction in government subsidies for each averted case of T2DM.

For utilisation by income quintile, we calculated the number of individuals currently taking DM medication as the percentage of those who reported being previously diagnosed with DM (see online supplementary appendix table A2).
Table 2 Input parameters used in the extended costeffectiveness analysis of introducing a sugar-sweetened beverage (SSB) tax in South Africa

\begin{tabular}{llc}
\hline Input & Value & Source \\
\hline $\begin{array}{l}\text { Tax, price and sugar content per litre } \\
\text { of SSB }\end{array}$ & \\
\hline $\begin{array}{ll}\text { Tax (ZAR cents) } \\
\text { of sugar over } \\
\text { 2.21 cents/g }\end{array}$ & National Treasury ${ }^{1112}$ \\
\hline $\begin{array}{l}\text { Sugar content } \\
\text { per litre (g) }\end{array}$ & $106 \mathrm{~g}$ & National Treasury ${ }^{1112}$ \\
\hline $\begin{array}{l}\text { Price per litre } \\
\text { Mortality due to } \\
\text { diabetes mellitus } \\
\text { (T2DM) as } \\
\text { percentage of all } \\
\text { deaths }\end{array}$ & $5.4 \%$ & National Treasury ${ }^{1112}$ \\
\hline
\end{tabular}

Relative risk of T2DM by age group per each unit increase in BMI

$\begin{array}{lll}<30 & 1.37 & \text { IHME }^{51} \\ 30-34 & 1.34 & \\ 35-39 & 1.32 \\ 40-44 & 1.29 \\ 45-49 & 1.27 \\ 50-54 & 1.24 \\ 55-59 & 1.22 \\ 60-64 & 1.20 \\ 65-69 & 1.18 \\ 70-74 & 1.15 \\ 75-79 & 1.13 \\ 80+ & 1.10\end{array}$

Average proportion of healthcare costs paid as OOP payment by income quintile

$\begin{array}{lll}\text { Quintile 1 } & 21 \% & \text { NIDS wave } 4^{47}, \\ \text { Quintile 2 } & 18 \% & \text { NDoH, } \\ \text { authors' calculations } \\ \text { Quintile 3 } & 41 \% & \\ \text { Quintile 4 } & 56 \% & \end{array}$

Income per capita quintiles in ZAR

\begin{tabular}{|c|c|c|}
\hline Quintile 1 & $<6486$ (US\$525) & NIDS wave $4^{47}$, \\
\hline Quintile 2 & $\begin{array}{l}6486 \text { to } 13818 \\
\text { (US\$525-US\$1119) }\end{array}$ & $\begin{array}{l}\mathrm{NDoH} \text {, authors' } \\
\text { calculations }\end{array}$ \\
\hline Quintile 3 & $\begin{array}{l}13819-28091 \\
\text { (US\$1119- } \\
\text { US\$2275) }\end{array}$ & \\
\hline Quintile 4 & $\begin{array}{l}28092-71478 \\
\text { (US\$2275- } \\
\text { US } \$ 5788)\end{array}$ & \\
\hline Quintile 5 & $\begin{array}{l}>71478 \\
\text { (US\$5788) }\end{array}$ & \\
\hline
\end{tabular}

Labour force participation rate 


\begin{tabular}{|c|c|c|}
\hline Input & Value & Source \\
\hline Quintile 1 & 0.51 & \multirow{5}{*}{$\begin{array}{l}\text { GHS }^{68} \text {, } \\
\text { authors' calculations }\end{array}$} \\
\hline Quintile 2 & 0.53 & \\
\hline Quintile 3 & 0.61 & \\
\hline Quintile 4 & 0.71 & \\
\hline Quintile 5 & 0.78 & \\
\hline \multicolumn{3}{|c|}{ Absenteeism and presenteeism ratios } \\
\hline $\begin{array}{l}\text { Number of } \\
\text { excess sick } \\
\text { days in a year }\end{array}$ & 8.6 & $\begin{array}{l}\text { Bommer et } a l^{57} \\
\text { based on data from } \\
\text { Guariguata et } a^{56}\end{array}$ \\
\hline $\begin{array}{l}\text { Productivity } \\
\text { shortfall }\end{array}$ & $0.6 \%$ & $\begin{array}{l}\text { Bommer et } a l^{57} \text { based } \\
\text { on data from Seuring } \\
\text { et } a l^{58}\end{array}$ \\
\hline
\end{tabular}

US\$1=ZAR12.35 (as of May 2018). Source: South Africa Revenue Service (SARS) available at http://tools.sars.gov.za/ rex/Rates/Default.aspx.

BMI, body mass index; GHS, General Household Survey; IHME, Institute for Health Metrics and Evaluation; NDoH, National Department of Health; NIDS, National Income Dynamics Study; OOP, out-of-pocket; T2DM, type 2 diabetes mellitus; ZAR, South African rand.

\section{Financial risk protection}

We used two measures of FRP. First, we used the catastrophic health expenditures (CHE) metric with disease-related expenditures exceeding $10 \%$ of total annual household expenditures and estimated the number of T2DM-related CHE cases avoided, with SSB tax introduction. ${ }^{54}$ Second, we used the number of poverty cases averted by estimating the number of cases avoiding their annual household income from dropping below the food poverty line (FPL) of ZAR321 or US\$21 per capita per month (see online supplementary appendix table A3 for definition of the three SA poverty line measures and their values).

\section{Change in additional tax revenues}

We used own price elasticity estimates and SSB consumption at baseline to obtain the post-tax SSB consumption by income quintile. This new SSB consumption was then multiplied by the tax rate per litre to derive the additional tax revenue collected from each income quintile.

\section{Indirect costs}

Following the human capital approach, we estimated indirect costs capturing the loss of income due to morbidity associated with T2DM, due to absenteeism (working days lost due to illness) and presenteeism (reduced productivity at work due to illness) ${ }^{55}$ Absenteeism was calculated by multiplying the number of excess sick days in a year (about 8.6 days), ${ }^{56}$ by the number of diabetics in the labour force and the average daily wage by income quintile. Presenteeism was calculated by multiplying the productivity shortfall $(0.6 \%)^{5758}$ by the number of diabetics in the labour force and by the average annual wage.

\section{Baseline characteristics and data sources}

We obtained population estimates by age from Statistics South Africa ${ }^{59}$ We calculated the share of each age population in each income quintile using wave 4 of the NIDS survey. ${ }^{47}$ We obtained age- and sex-specific population BMI and average height from the NIDS. SSB consumption was obtained from the All Media and Products Survey for $2013 .^{60}$ The mean annual salary and labour force participation rates (LFPR) were estimated from the 2015 General Household Survey (GHS). The healthcare utilisation measure was constructed using the 2015 GHS.

\section{Sensitivity analyses}

We conducted five univariate sensitivity analyses: (1) we reduced the tax pass-through effect from $100 \%$ to $60 \%$; (2) we altered sugar content as the producers of SSB may reduce the sugar content in response to the tax; (3) for determining CHE cases we used two different thresholds ( 5 and $40 \%$ ) in place of the $10 \%$ threshold used in the base case; (4) we varied the utilisation for health services for each quintile; (5) instead of using the average wages by income quintile, we calculated the indirect costs using the recently approved minimum wage in SA of ZAR20 per hour. ${ }^{61}$

The pass-through rate could be different over time, across the type and location of retail stores and across countries. Evidence from SA shows that for taxes on beer, the pass-through rate of taxes to retail prices was greater than $100 \% .{ }^{25}$ For SSBs, one study from Berkeley (USA) showed that in the first month the prices of SSBs increased by $61 \%$ and in the second month they increased by $93 \%$ in the retail stores that had to implement the tax due to their geographical location. ${ }^{23}$ Thus, to observe the short-term impact, we used the estimate for the pass-through effect in the shortest observed duration (60\% over first month) in our sensitivity analysis. The producers may reduce the SSB sugar content and we considered two scenarios: reductions of sugar content by 10 and 20\%, respectively. Reduction in sugar content will also reduce the quantum of price increase per litre of SSB as the tax is imposed on the quantity of sugar per litre of SSB. We assumed that benefits from this reduction in sugar content would be derived entirely from reduction in sugar intake and its energy conversion and not through reduction in consumption due to change in taste of SSB with lower sugar content.

For utilisation, we adopted a traditional measure of health services utilisation by calculating the percentage of individuals who reported being ill (with any disease condition) that had accessed health services in the past 30 days (see online supplementary appendix table A2). The mean utilisation was $60 \%$ with lowest utilisation of $53 \%$ in the bottom quintile and highest utilisation of $70 \%$ in the top quintile. The last sensitivity analysis of using minimum wage across all quintiles instead of average wage in each quintile provided an estimation of the T2DM economic burden as a function of LFPR and 
Table 3 Summary findings for the extended cost-effectiveness analysis of $10 \%$ tax on sugar-sweetened beverages in South Africa

\begin{tabular}{lllllll}
\hline & Total & Quintile 1 & Quintile 2 & Quintile 3 & Quintile 4 & Quintile 5 \\
\hline T2DM deaths averted* & 7898 & 1260 & 1561 & 1820 & 1860 & 1397 \\
\hline $\begin{array}{l}\text { Government healthcare savings (ZAR million)* } \\
\text { Changes in annual tax revenues (ZAR million) }\end{array}$ & 1690 & 383 & 488 & 410 & 314 & 94 \\
\hline $\begin{array}{l}\text { Financial risk protection (cases of poverty } \\
\text { averted using FPL)* }\end{array}$ & 12179 & 1155 & 5595 & 5066 & 363 & 0 \\
$\begin{array}{l}\text { Financial risk protection (cases of catastrophic } \\
\text { expenditures averted)* }\end{array}$ & 32377 & 6455 & 7020 & 8760 & 6418 & 3724 \\
$\begin{array}{l}\text { Annual indirect cost savings } \\
\text { (ZAR million) }\end{array}$ & 11.1 & 0.2 & 0.6 & 0.9 & 2.0 & 7.4 \\
\hline
\end{tabular}

*Estimated over 20 years.

FPL, food poverty line (ZAR321 or US\$21 per capita per month); T2DM, type 2 diabetes mellitus; ZAR, South African rand.

T2DM incidence by quintile, and avoided ascribing more value to individuals with higher wages.

\section{Patient and public involvement}

No patients were involved in this study.

\section{RESULTS}

We present our findings by income quintile on: the number of T2DM-related premature deaths averted, the reduction in OOP payments, the additional tax revenues collected by the government, the cases of CHE averted and the savings in indirect costs (table 3 ).

Figure 3 presents the distribution of premature T2DM-related deaths averted due to a $10 \%$ SSB tax over 20 years. We estimated that 8000 deaths could be averted, and the effect would be concentrated in the third and fourth income quintiles with $47 \%$ of the deaths averted accruing in those two quintiles. The smallest effect would be among the lowest quintile with slightly more than

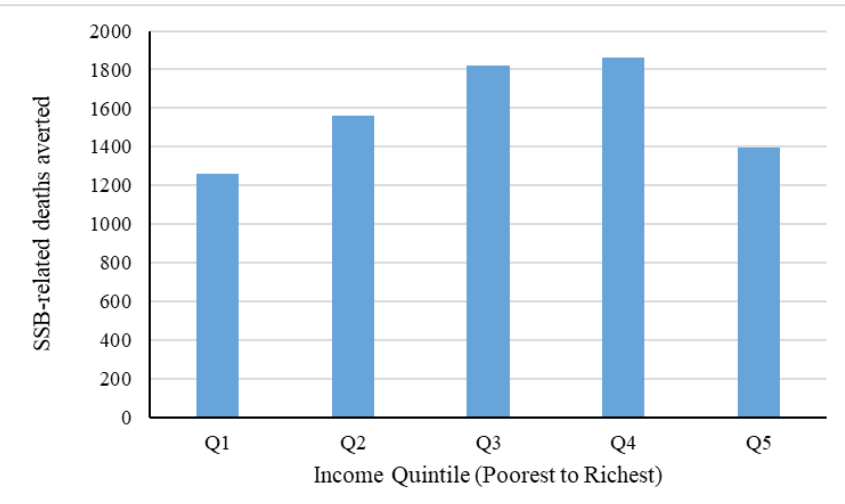

Figure 3 Estimated distribution of potential type 2 diabetes mellitus (T2DM)-related deaths averted over a 20-year time period, with a $10 \%$ tax on sugar-sweetened beverage (SSB) prices. This figure shows the distribution across income quintiles of potential T2DM-related deaths averted due to a $10 \%$ tax on SSB prices over a 20 -year time period in South Africa. Q1 refers to lowest income quintile, Q5 refers to highest income quintile.
1200 deaths averted (16\% of the total deaths averted). The low magnitude of effect in the lowest quintile could be due to the relatively lower levels of SSB consumption as compared with other quintiles.

Regarding reductions in OOP payments and government subsidies (figure 4), our analysis shows a reduction of ZAR1.3 billion over 20 years in OOP payments related to T2DM treatment. Since the lowest two income quintiles would pay on average $20 \%$ of their healthcare costs in OOP payments, the reduction would be smaller in these two quintiles $(8 \%$ of total reduction in each quintile); $63 \%$ of the savings would accrue to the top two quintiles as they are required to pay $56-82 \%$ of their healthcare costs: OOP savings for the top two quintiles would be ZAR400 million and ZAR440 million (30\% and $33 \%$ of the total reduction, respectively). Furthermore,

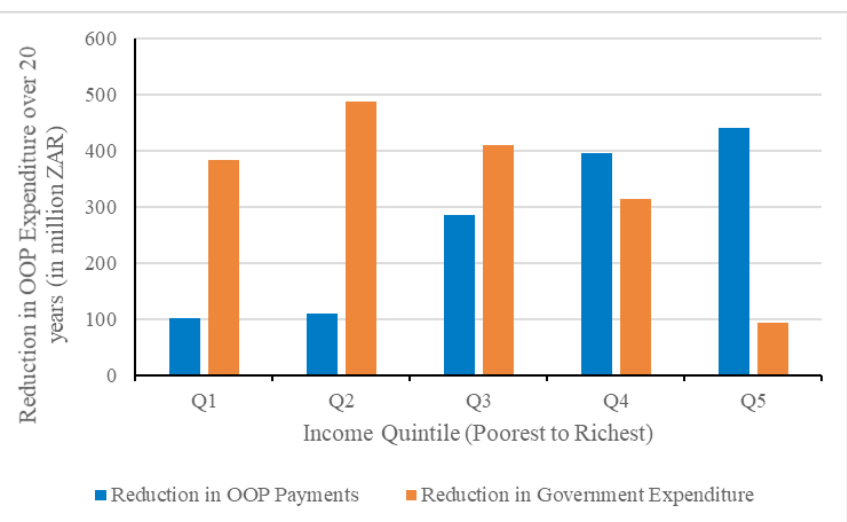

Figure 4 Estimated distribution of the reduction of outof-pocket (OOP) payments and government expenditures related to type 2 diabetes mellitus (T2DM) healthcare costs by income quintile, in South Africa, over a 20-year time period. This figure shows the distribution across income quintiles of reductions in OOP expenditures and government expenditures on subsidies that are related to T2DM healthcare costs due to $10 \%$ tax on sugar-sweetened beverages over a 20-year time period in South Africa. Q1 refers to lowest income quintile, Q5 refers to highest income quintile. ZAR, South African rand. 


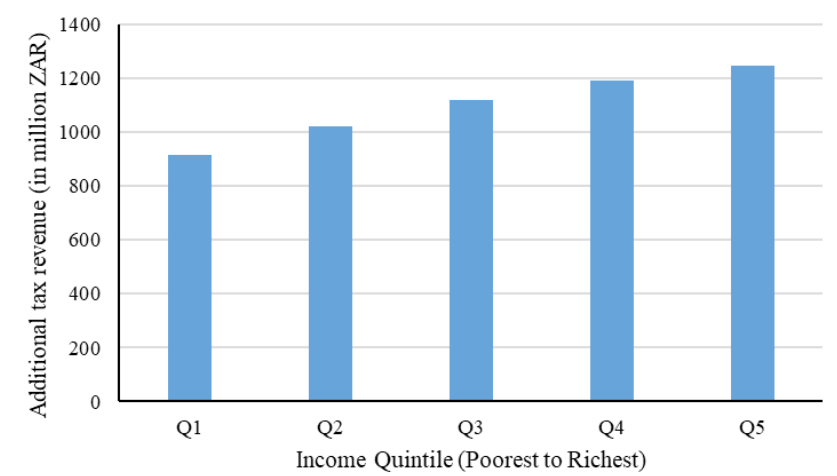

Figure 5 Estimated distribution of additional tax revenues by income quintile with the sugar-sweetened beverage (SSB) 10\% tax in South Africa, per annum. This figure shows the distribution across income quintiles of additional tax revenues collected per annum due to a 10\% tax on SSB prices in South Africa. Q1 refers to lowest income quintile, Q5 refers to highest income quintile. ZAR, South African rand.

the government would save about ZAR1.7 billion in subsidies over 20 years representing about $4 \%$ of SA's Department of Health's 2017/2018 annual expenditures.

Despite the expected reduction in SSB consumption, we estimated that the government would receive ZAR5.5 billion per annum as additional tax revenues. The price elasticity for consumption is relatively low (in absolute value) in the richest quintile, where the smallest reduction in consumption would be expected. Consequently, this income group would bear about $23 \%$ of the tax revenues (figure 5). Quintiles 4 and 5 would bear $45 \%$ of the tax revenues. The bottom two income quintiles (quintiles 1 and 2) have relatively higher elastic demand and lower per-capita SSB consumption, and would contribute to a total $35 \%$ of the tax revenues.

For FRP, using the FPL (ZAR321 per capita per month), about 1100 cases of poverty would be averted in the poorest quintile, while around 400 cases would be averted in the fourth quintile and none in the highest quintile (figure 6). As the average T2DM treatment cost was almost $25 \%$ of annual household expenditures (annual household expenditures for a three-person household was about ZAR103,290 (US\$8370) with an annual cost of ZAR27,000), any reduction in treatment cost would likely have a significant impact on averting CHEs. We estimated that this tax policy would likely avert 6500 cases of CHE in the lowest quintile (20\% of all cases averted). The number of CHE cases averted would increase to about 8700 for quintile 3 (27\% of all cases). For the highest income quintile, we would observe about 3700 cases of CHE averted (12\% of all cases).

Lastly, savings in indirect costs due to reduced absenteeism and presenteeism would amount to ZAR11 million per annum. The major share of these savings (ZAR7million) would accrue to the highest income quintile due to the higher per-capita wage in this

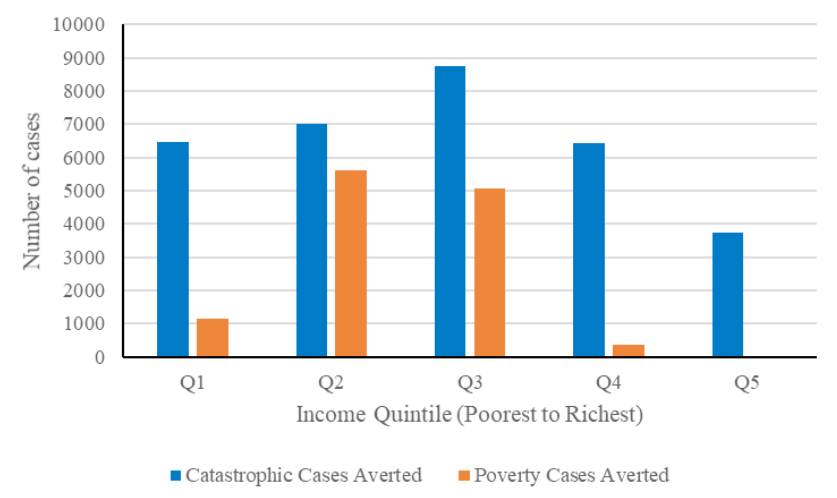

Figure 6 Estimated number of catastrophic health expenditures and poverty cases averted over a 20-year time period, with the introduction of the sugar-sweetened beverage (SSB) tax in South Africa. This figure shows the distribution across income quintiles of catastrophic health expenditures averted and poverty cases averted due to $10 \%$ tax on SSB prices in South Africa. For determining catastrophic health expenditures, this figure uses the criterion of disease expenditures exceeding $10 \%$ of annual household expenditures. For determining poverty cases, this figure uses the food poverty line of South African rand (ZAR) 321 (US\$21) per capita per month. Q1 refers to lowest income quintile, Q5 refers to highest income quintile.

quintile, whereas the lowest income quintile would only have savings of $<$ ZAR1 million.

\section{Sensitivity analyses}

In reducing the tax pass-through effect to a lower bound of $60 \%$, we would observe changes in effects in both absolute and distributional terms. The total number of T2DM premature deaths averted would be reduced to 3200 (from 7800), about 59\% lower than in the base case scenario (table 4); but we observed an increase in tax revenues to ZAR5.8 billion. Lastly, we estimated that 5000 poverty cases (using FPL) and 13,000 CHE cases would be averted (a reduction from 12,000 and 32,000 respectively).

In considering the impact of SSB sugar content reduction by producers in response to the tax, we re-estimated the model assuming $10 \%$ and $20 \%$ reduction in sugar content. A $10 \%$ reduction in sugar content is likely to reduce the T2DM-related deaths by 4600 while a $20 \%$ reduction in sugar content is estimated to reduce the deaths by 7000 as compared with 7800 deaths averted under the base case scenario. This policy would also reduce the annual tax revenues from ZAR5490 million in the base case scenario to ZAR2361 million (10\% reduction in sugar content) and ZAR2842 million (20\% reduction in sugar content).

For health services utilisation, when adopting utilisation rates for those who are ill and access healthcare services within 30 days, the FRP benefits (ie, the number of poverty cases and CHE cases averted) would be reduced (table 5). 
Table 4 Sensitivity analyses for pass-through rate and reduction in sugar content for the extended cost-effectiveness analysis of $10 \%$ tax on sugar-sweetened beverages in South Africa

\begin{tabular}{|c|c|c|c|c|c|c|}
\hline & Total & Quintile 1 & Quintile 2 & Quintile 3 & Quintile 4 & Quintile 5 \\
\hline \multicolumn{7}{|l|}{ Panel A. Pass-through effect reduced to $60 \%$} \\
\hline T2DM deaths averted* & 3233 & 518 & 650 & 748 & 757 & 559 \\
\hline Government healthcare savings (ZAR million)* & 696 & 158 & 203 & 169 & 128 & 38 \\
\hline Changes in annual tax revenues (ZAR million) & 5775 & 968 & 1077 & 1179 & 1253 & 1299 \\
\hline $\begin{array}{l}\text { Financial risk protection (cases of poverty } \\
\text { averted using } \mathrm{FPL})^{*}\end{array}$ & 4994 & 436 & 2335 & 2069 & 154 & 0 \\
\hline $\begin{array}{l}\text { Financial risk protection (cases of catastrophic } \\
\text { expenditures averted) }\end{array}$ & 13277 & 2664 & 2926 & 3601 & 2612 & 1474 \\
\hline Annual indirect cost savings (ZAR million) & 4.6 & 0.1 & 0.2 & 0.4 & 0.8 & 3.1 \\
\hline \multicolumn{7}{|l|}{ Panel B. $10 \%$ reduction in sugar content } \\
\hline T2DM deaths averted* & 4642 & 687 & 951 & 1107 & 1119 & 779 \\
\hline Government healthcare savings (ZAR million)* & 997 & 209 & 297 & 250 & 189 & 53 \\
\hline Changes in annual tax revenues (ZAR million) & 2361 & 394 & 440 & 481 & 512 & 534 \\
\hline $\begin{array}{l}\text { Financial risk protection (cases of poverty } \\
\text { averted using } \mathrm{FPL})^{*}\end{array}$ & 7330 & 645 & 3390 & 3066 & 229 & 0 \\
\hline $\begin{array}{l}\text { Financial risk protection (cases of catastrophic } \\
\text { expenditures averted) })^{*}\end{array}$ & 18990 & 3512 & 4250 & 5308 & 3860 & 2060 \\
\hline Annual indirect cost savings (ZAR million) & 6.1 & 0.1 & 0.3 & 0.5 & 1.1 & 4.0 \\
\hline \multicolumn{7}{|l|}{ Panel C. $20 \%$ reduction in sugar content } \\
\hline T2DM deaths averted* & 7007 & 1338 & 1349 & 1563 & 1615 & 1143 \\
\hline Government healthcare savings (ZAR million)* & 1530 & 407 & 421 & 352 & 273 & 77 \\
\hline Changes in annual tax revenues (ZAR million) & 2842 & 473 & 528 & 579 & 617 & 646 \\
\hline $\begin{array}{l}\text { Financial risk protection (cases of poverty } \\
\text { averted using } \mathrm{FPL})^{*}\end{array}$ & 10633 & 1204 & 4824 & 4310 & 295 & 0 \\
\hline $\begin{array}{l}\text { Financial risk protection (cases of catastrophic } \\
\text { expenditures averted) })^{\star}\end{array}$ & 29000 & 6878 & 6038 & 7499 & 5529 & 3056 \\
\hline Annual indirect cost savings (ZAR million) & 11.9 & 0.3 & 0.6 & 1.0 & 2.1 & 7.9 \\
\hline
\end{tabular}

${ }^{\star}$ Estimated over 20 years.

FPL, food poverty line (ZAR321 or US\$21 per capita per month); T2DM, type 2 diabetes mellitus; ZAR, South African rand.

When assigning a minimum wage of ZAR20 per hour to individuals across all income quintiles instead of using mean wage per quintile, the total productivity losses would decline to ZAR9 million per annum. The distribution of productivity losses would, expectedly, be more uniform across quintiles (table 5).

Furthermore, while using a 10\% threshold, the number of CHE averted would be 32000 whereas under a $40 \%$ threshold, it would reduce to 10000 and under a 5\% threshold it would increase to 38000 (table 6). Using the upper bound poverty line (UB-PL) value (ZAR620 per capita per month) we estimated about 12130 poverty cases averted in quintiles 2 and 3. The UB-PL value of ZAR620 per capita per month (ZAR7440 per annum) is about $15 \%$ higher than the upper bound cut-off value of per-capita income for the lowest income quintile (6485 per annum), and thus there would be no cases of poverty averted in this group.

\section{DISCUSSION}

SSB consumption has been linked with several obesity-related NCDs, including T2DM, certain cancers, dental caries and cardiovascular diseases. Evidence from other countries suggests that a tax on SSBs is likely to reduce consumption and reduce the increasing burden of obesity-related NCDs. In 2018, the South African government implemented a $10 \%$ excise tax on SSBs. This is expected to reduce the consumption of SSBs, related obesity and associated NCD conditions, including T2DM, and premature deaths. It is also anticipated to reduce public sector expenditures subsidising the treatment of NCDs and is expected to raise revenues.

As the number of countries considering and implementing SSB tax is increasing, there have been a number of studies modelling the potential impact of such tax on SSB consumption, obesity prevalence, disease incidence and mortality. However, most of these studies have not considered the distributional impact of the SSB tax. Only 
Table 5 Sensitivity analyses for healthcare utilisation rate and wage rate for the extended cost-effectiveness analysis of $10 \%$ tax on sugar-sweetened beverages in South Africa

Total Quintile 1 Quintile 2 Quintile 3 Quintile 4 Quintile 5

\begin{tabular}{|c|c|c|c|c|c|c|}
\hline T2DM deaths averted* & 5153 & 735 & 954 & 1154 & 1226 & 1084 \\
\hline Government healthcare savings (ZAR million) $)^{\star}$ & 1062 & 223 & 298 & 260 & 207 & 73 \\
\hline Changes in annual tax revenues (ZAR million) & 5490 & 915 & 1021 & 1118 & 1191 & 1245 \\
\hline $\begin{array}{l}\text { Financial risk protection (cases of poverty } \\
\text { averted using FPL)* }\end{array}$ & 7536 & 675 & 3389 & 3227 & 245 & 0 \\
\hline $\begin{array}{l}\text { Financial risk protection (cases of catastrophic } \\
\text { expenditures averted)* }\end{array}$ & 20736 & 3763 & 4289 & 5553 & 4222 & 2909 \\
\hline Annual indirect cost savings (ZAR million) & 12.2 & 0.3 & 0.6 & 1.0 & 2.2 & 8.1 \\
\hline \multicolumn{7}{|c|}{ Panel B. Wage set to minimum wage across all quintiles } \\
\hline T2DM deaths averted ${ }^{*}$ & 7898 & 1260 & 1561 & 1820 & 1860 & 1397 \\
\hline Government healthcare savings (ZAR million) ${ }^{*}$ & 1690 & 383 & 488 & 410 & 314 & 94 \\
\hline Changes in annual tax revenues (ZAR million) & 5490 & 915 & 1021 & 1118 & 1191 & 1245 \\
\hline $\begin{array}{l}\text { Financial risk protection (cases of poverty } \\
\text { averted using FPL)* }\end{array}$ & 12179 & 1155 & 5595 & 5066 & 363 & 0 \\
\hline $\begin{array}{l}\text { Financial risk protection (cases of catastrophic } \\
\text { expenditures averted) }\end{array}$ & 32377 & 6455 & 7020 & 8760 & 6418 & 0 \\
\hline Annual indirect cost savings (ZAR million) & 9.4 & 1.2 & 1.6 & 2.1 & 2.5 & 2.0 \\
\hline
\end{tabular}

*Estimated over 20 years.

FPL, food poverty line (ZAR321 or US\$21 per capita per month); T2DM, type 2 diabetes mellitus; ZAR, South African rand.

two recent studies from Australia and Indonesia have modelled the impact along income quintiles. ${ }^{48} 62$ Even in SA, a few studies had modelled the population-wide impact of SSB tax on disease mortality. ${ }^{31-35}$ Our study is one of the first to model the potential distributional health and financial impacts of SSB taxes among poor

Table 6 Sensitivity analyses for catastrophic health expenditure thresholds for the extended cost-effectiveness analysis of $10 \%$ tax on sugar-sweetened beverages in South Africa

\section{Total Quintile 1 Quintile 2 Quintile 3 Quintile 4 Quintile 5}

\begin{tabular}{|c|c|c|c|c|c|c|}
\hline \multicolumn{7}{|c|}{ Panel A. Catastrophic health expenditure threshold set to $5 \%$} \\
\hline T2DM deaths averted* & 7898 & 1260 & 1561 & 1820 & 1860 & 1397 \\
\hline 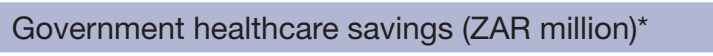 & 1690 & 383 & 488 & 410 & 314 & 94 \\
\hline Changes in annual tax revenues (ZAR million) & 5490 & 915 & 1021 & 1118 & 1191 & 1245 \\
\hline $\begin{array}{l}\text { Financial risk protection (cases of poverty averted } \\
\text { using FPL)* }\end{array}$ & 12179 & 1155 & 5595 & 5066 & 363 & 0 \\
\hline $\begin{array}{l}\text { Financial risk protection (cases of catastrophic } \\
\text { expenditures averted)* }\end{array}$ & 38068 & 6455 & 7020 & 8760 & 8809 & 7024 \\
\hline Annual indirect cost savings (ZAR million) & 11.1 & 0.2 & 0.6 & 0.9 & 2.0 & 7.4 \\
\hline \multicolumn{7}{|c|}{ Panel B. Catastrophic health expenditure threshold set to $40 \%$} \\
\hline T2DM deaths averted* & 7898 & 1260 & 1561 & 1820 & 1860 & 1397 \\
\hline 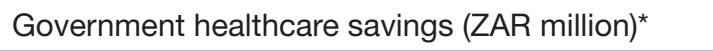 & 1690 & 383 & 488 & 410 & 314 & 94 \\
\hline Changes in annual tax revenues (ZAR million) & 5490 & 915 & 1021 & 1118 & 1191 & 1245 \\
\hline $\begin{array}{l}\text { Financial risk protection (cases of poverty averted } \\
\text { using FPL)* }\end{array}$ & 12179 & 1155 & 5595 & 5066 & 363 & 0 \\
\hline $\begin{array}{l}\text { Financial risk protection (cases of catastrophic } \\
\text { expenditures averted)* }\end{array}$ & 10107 & 6360 & 242 & 3505 & 0 & 0 \\
\hline Annual indirect cost savings (ZAR million) & 11.1 & 0.2 & 0.6 & 0.9 & 2.0 & 7.4 \\
\hline
\end{tabular}

*Estimated over 20 years.

FPL, food poverty line (ZAR321 or US\$21 per capita per month); T2DM, type 2 diabetes mellitus; ZAR, South African rand. 
and rich households in SA using ECEA. Inequality, and especially health inequality, is still an important challenge in SA. ECEA enables us to disaggregate the population-wide impact of an intervention into effects by income quintile and on inequality. ECEA also enables us to analyse the potential regressivity of this economic intervention beyond the sole consideration of tax incidence by extending the analysis to health benefits and financial protection.

In this study, we showed that the recently implemented SA SSB tax could have the potential to reduce T2DM-related deaths. We found that the tax would reduce T2DM deaths with the greatest impact among the third and fourth income quintiles due to the relatively larger amount of SSB consumption in these groups. The reduction in OOP expenditures would be lowest in the bottom quintile and highest in the top quintile. This is reflective of the means-tested subsidies that are provided largely to households with low income, and is a testimony to the pro-poor orientation of the current South African health system. However, due to SA's skewed income distribution, these reductions in OOP expenditures still result in significant reductions in CHE-related poverty cases.

Nevertheless, our study presents several limitations. First, we did not have direct estimates of the price elasticity of SSB consumption by income quintile. Instead, we used Mexican estimates and regressed them on upper bound values of income quintiles in SA to obtain quintile-specific elasticity estimates. The median of our scaled estimates was close to a previously identified average price elasticity in SA. Second, we did not include consideration of substitution from SSBs to other potential drink substitutes such as milk and $100 \%$ fruit juices, neither did we consider the effect of reduced consumption of potential complements to SSBs such as junk food. This is in part due to a lack of empirical estimates and expert consensus on cross-price elasticities. To the extent that substitution patterns result in positive or negative net changes in caloric intake our results would either overstate or understate the health impact of the tax. Third, as we built on previous analyses of SSB tax from $\mathrm{SA}^{31-36}$ we only estimated the health impact of the tax on T2DM-related mortality. Consumption of SSBs and obesity are associated with several diseases and conditions like cardiovascular diseases and certain types of cancers (oesophageal, colon, breast, liver, pancreatic). In addition, in our estimation of indirect costs, we only accounted for absenteeism and presenteeism, but not for labour force dropout, premature mortality and other indirect costs such as caregiver costs. Lastly, while we acknowledge that there is heterogeneity across racial groups (as observed in the USA) in terms of SSB consumption, price elasticity, BMI distribution, disease incidence and metabolic response, ${ }^{63}$ we only modelled the average population effects by using population averages across all racial groups in SA, as the overwhelming majority of South Africans are Black Africans (about $81 \%)^{44}$ and due to data limitations and unavailability of modelling parameters suitable for SA.
The evidence on differential metabolic response by Black and White races was also inconclusive and largely based on studies in the USA. ${ }^{64-66}$ We did not have sufficient respondents in each race, sex, age and quintile category in NIDS to calculate mean SSB consumption, BMI and height; and we did not have separate elasticity measures across racial groups; neither did we have separate distributions in disease prevalence, incidence and mortality by race in SA. As a result, analyses disaggregated across racial groups in SA are left for future work once data and evidence become available.

An important conclusion from this analysis is that SA's SSB tax has the potential to reduce deaths due to T2DM, reduce OOP and government expenditures, and healthcare expenditure-induced poverty. As tax policy is being implemented, further evaluation is required to determine its impact on price changes, the response from sugar producers on content in SSBs, the impact on other obesity-related NCDs and to measure these among the South African population to ascertain the distributional benefits of the policy.

Acknowledgements We thank the International Development Research Center for funding. Preliminary versions of this paper were presented during seminars at the University of the Witwatersrand School of Public Health and the Harvard TH Chan School of Public Health where we received valuable comments from seminar participants.

Contributors SV, NS and KH conceived the study. SV supervised the study. AS, NS, $\mathrm{CM}$ and PDRP collected the data. AS performed the calculations and interpreted the results with SV and NS. AS wrote the first draft of the manuscript. All authors reviewed and edited the manuscript. The corresponding author had full access to all the data in the study and had the final responsibility for the decision to submit for publication.

Funding This work was funded by the International Development Research Centre (grant\#108424-001).

Disclaimer The funder had no role in the study design, data collection, data analysis, data interpretation or writing of the report.

Competing interests None declared.

Patient consent for publication Not required.

Provenance and peer review Not commissioned; externally peer reviewed.

Data availability statement Data are publicly available.

Open access This is an open access article distributed in accordance with the Creative Commons Attribution Non Commercial (CC BY-NC 4.0) license, which permits others to distribute, remix, adapt, build upon this work non-commercially, and license their derivative works on different terms, provided the original work is properly cited, appropriate credit is given, any changes made indicated, and the use is non-commercial. See: http://creativecommons.org/licenses/by-nc/4.0/.

\section{REFERENCES}

1. Statistics South Africa. Demographic and health survey 2016: key indicators report. Pretoria: Statistics South Africa; 2017.

2. National Department of Health, Republic of South Africa. Strategic plan for the prevention and control of non-communicable diseases. Pretoria: National Department of Health; 2013.

3. Hu FB. Resolved: there is sufficient scientific evidence that decreasing sugar-sweetened beverage consumption will reduce the prevalence of obesity and obesity-related diseases. Obes Rev 2013;14:606-19.

4. Malik VS, Pan A, Willett WC, et al. Sugar-Sweetened beverages and weight gain in children and adults: a systematic review and metaanalysis. Am J Clin Nutr 2013;98:1084-102.

5. Malik VS, Popkin BM, Bray GA, et al. Sugar-Sweetened beverages, obesity, type 2 diabetes mellitus, and cardiovascular disease risk. Circulation 2010;121:1356-64. 
6. Malik VS, Schulze MB, Hu FB. Intake of sugar-sweetened beverages and weight gain: a systematic review. Am J Clin Nutr 2006;84:274-88.

7. Koo WW, Taylor RD. Outlook of the U.S. and world sugar markets, 2011-2021. St Louis Federal Reserve Bank of St Louis; 2012.

8. South African Sugar Association. Available: http://www.sasa.org. za/Libraries/facts figures_2014-2015/National_Market_Sugar Consumption.sflb.ashx

9. Euromonitor International. Soft drinks in South Africa, 2015 Euromonitor Passport database. Available: Retrieved from: www. euromonitor.com [Accessed 12 Mar 2017]

10. Blecher E, Liber AC, Drope JM, et al. Global trends in the affordability of sugar-sweetened beverages, 1990-2016. Prev Chronic Dis 2017;14:E37.

11. National Treasury. Taxation of sugar-sweetened beverages. Pretoria: National Treasury; 2016

12. National Treasury. Budget review 2018. Pretoria National Treasury; 2018

13. World Health Organization. Diet, nutrition, and prevention of chronic diseases: report of a joint WHO/FAO expert consultation, Geneva, 28 January-1 February 2002. Geneva: World Health Organization Technical Report Series 916; 2003.

14. World Health Organization. Fiscal policies for diet and the prevention of noncommunicable diseases. Geneva: World Health Organization, 2016.

15. Baker P, Jones A, Thow AM. Accelerating the Worldwide Adoption of Sugar-Sweetened Beverage Taxes: Strengthening Commitment and Capacity Comment on "The Untapped Power of Soda Taxes: Incentivizing Consumers, Generating Revenue, and Altering Corporate Behavior". Int J Health Policy Manag 2017;7:474-8.

16. Colchero MA, Popkin BM, Rivera JA, et al. Beverage purchases from stores in Mexico under the excise tax on sugar sweetened beverages: observational study. BMJ 2016;352.

17. Colchero MA, Molina M, Guerrero-López CM. After Mexico implemented a tax, purchases of sugar-sweetened beverages decreased and water increased: difference by place of residence, household composition, and income level. J Nutr 2017;147:1552-7.

18. Alvarado M, Kostova D, Suhrcke $M$, et al. Trends in beverage prices following the introduction of a tax on sugar-sweetened beverages in Barbados. Prev Med 2017;105:S23-S25.

19. Falbe J, Rojas N, Grummon AH, et al. Higher retail prices of sugarsweetened beverages 3 months after implementation of an excise tax in Berkeley, California. Am J Public Health 2015;105:2194-201.

20. Silver LD, Ng SW, Ryan-lbarra S, et al. Changes in prices, sales, consumer spending, and beverage consumption one year after a tax on sugar-sweetened beverages in Berkeley, California, US: a beforeand-after study. PLoS Med 2017;14:e1002283.

21. Berardi N, Sevestre P, Tépaut M, et al. The impact of a 'soda tax' on prices: evidence from French micro data. Appl Econ 2016;48:3976-94

22. Colchero MA, Salgado JC, Unar-Munguía M, et al. Price elasticity of the demand for sugar sweetened beverages and soft drinks in Mexico. Econ Hum Biol 2015;19:129-37.

23. Cawley J, Willage B, Frisvold D. Pass-through of a tax on sugarsweetened beverages at the Philadelphia International Airport. JAMA 2018;319:305-6.

24. Grogger J. Soda taxes and the prices of sodas and other drinks: evidence from Mexico. NBER working paper No. 21197, 2015.

25. Russell C, van Walbeek C. How does a change in the excise tax on beer impact beer retail prices in South Africa? South African Journal of Economics 2016;84:555-73.

26. Mayosi BM, Benatar SR. Health and health care in South Africa--20 years after Mandela. N Engl J Med 2014;371:1344-53.

27. Mayosi BM, Flisher AJ, Lalloo UG, et al. The burden of non-communicable diseases in South Africa. The Lancet 2009;374:934-47.

28. World Bank. Overcoming poverty and inequality in South Africa: an assessment of drivers, constraints and opportunities. Washington, DC: World Bank, 2018.

29. Davis R. Will sugar tax penalise the poor for their sweet tooth? Both sides get all a-fizz. Mail and Guardian 2016.

30. Backholer K, Sarink D, Beauchamp A, et al. The impact of a tax on sugar-sweetened beverages according to socio-economic position: a systematic review of the evidence. Public Health Nutr 2016;19:3070-84.

31. Manyema M, Veerman JL, Chola L, et al. Decreasing the burden of type 2 diabetes in South Africa: the impact of taxing sugarsweetened beverages. PLoS One 2015;10:e0143050.

32. Manyema M, Veerman LJ, Chola L, et al. The potential impact of a $20 \%$ tax on sugar-sweetened beverages on obesity in South African adults: a mathematical model. PLoS One 2014:9:e105287.
33. Manyema M, Veerman LJ, Tugendhaft A, et al. Modelling the potential impact of a sugar-sweetened beverage tax on stroke mortality, costs and health-adjusted life years in South Africa. BMC Public Health 2016;16:405.

34. Tugendhaft $A$, Manyema M, Veerman LJ, et al. Cost of inaction on sugar-sweetened beverage consumption: implications for obesity in South Africa. Public Health Nutr 2016;19:2296-304.

35. Stacey N, Summan A, Tugendhaft A, et al. Simulating the impact of excise taxation for disease prevention in low-income and middleincome countries: an application to South Africa. BMJ Glob Health 2018;3:e000568.

36. Stacey N, Tugendhaft A, Hofman K. Sugary beverage taxation in South Africa: household expenditure, demand system elasticities, and policy implications. Prev Med 2017;105(Supplement):S26-S31.

37. Verguet S, Kim JJ, Jamison DT. Extended cost-effectiveness analysis for health policy assessment: a tutorial. Pharmacoeconomics 2016;34:913-23.

38. Verguet S, Laxminarayan R, Jamison DT. Universal public finance of tuberculosis treatment in India: an extended cost-effectiveness analysis. Health Econ 2015;24:318-32.

39. Verguet S, Gauvreau CL, Mishra S, et al. The consequences of tobacco tax on household health and finances in rich and poor smokers in China: an extended cost-effectiveness analysis. Lancet Glob Health 2015;3:e206-16.

40. Postolovska I, Lavado R, Tarr G, et al. The health gains, financial risk protection benefits, and distributional impact of increased tobacco taxes in Armenia. Health Systems \& Reform 2018;4:30-41.

41. James EK, Saxena A, Franco Restrepo C, et al. Distributional health and financial benefits of increased tobacco taxes in Colombia: results from a modelling study. Tob Control 2019;28:374-80.

42. Salti N, Brouwer E, Verguet S. The health, financial and distributional consequences of increases in the tobacco excise tax among smokers in Lebanon. Soc Sci Med 2016;170:161-9.

43. Verguet S, Tarr G, Gauvreau CL, et al. Distributional benefits of tobacco tax and smoke-free workplaces in China: a modeling study. J Glob Health 2017;7:020701.

44. Statistics South Africa. Mid-year population estimates 2018, in statistical release P0302. Pretoria: Statistics South Africa, 2018.

45. Imamura F, O'Connor L, Ye Z, et al. Consumption of sugar sweetened beverages, artificially sweetened beverages, and fruit juice and incidence of type 2 diabetes: systematic review, metaanalysis, and estimation of population attributable fraction. $B M J$ 2015;351:h3576.

46. Hall KD, Sacks G, Chandramohan D, et al. Quantification of the effect of energy imbalance on bodyweight. The Lancet 2011;378:826-37.

47. National income dynamics study 2014/2015. Cape Town Southern Africa Labour and Development Research Unit; 2015.

48. Lal A, Mantilla-Herrera AM, Veerman L, et al. Modelled health benefits of a sugar-sweetened beverage tax across different socioeconomic groups in Australia: a cost-effectiveness and equity analysis. PLoS Med 2017:14:e1002326.

49. Veerman JL, Sacks G, Antonopoulos N, et al. The impact of a tax on sugar-sweetened beverages on health and health care costs: a modelling study. PLoS One 2016;11:e0151460.

50. Saxena A, Koon AD, Lagrada-Rombaua $L$, et al. Modelling the impact of a tax on sweetened beverages in the Philippines: an extended cost-effectiveness analysis. Bull World Health Organ 2019;97:97-107.

51. Afshin A, Forouzanfar MH, Reitsma MB, et al. Health effects of overweight and obesity in 195 countries over 25 years. N Engl J Med 2017;377:13-27.

52. Barendregt $\mathrm{JJ}$, Veerman $\mathrm{JL}$. Categorical versus continuous risk factors and the calculation of potential impact fractions. $J$ Epidemiol Community Health 2010;64:209-12.

53. National Department of Health, South Africa. Uniform patient fee schedule user guide. Pretoria: National Department of Health; 2012.

54. O'Donnell O, van Doorslaer E, Wagstaff A, et al. Catastrophic Payments for Health Care. In: Analyzing health equity using household survey data: a guide to techniques and their implementation. Washington DC: The World Bank, 2008: 203-12.

55. Liljas B. How to calculate indirect costs in economic evaluations. Pharmacoeconomics 1998:13:1-7.

56. Guariguata L, de Beer I, Hough R, et al. Diabetes, HIV and other health determinants associated with absenteeism among formal sector workers in Namibia. BMC Public Health 2012;12:44.

57. Bommer C, Heesemann E, Sagalova V, et al. The global economic burden of diabetes in adults aged 20-79 years: a cost-of-illness study. Lancet Diabetes Endocrinol 2017;5:423-30. 
58. Seuring T, Serneels $P$, Suhrcke $M$. The impact of diabetes on labor market outcomes in Mexico: a panel data and biomarker analysis. IZA Discussion Paper No. 10123 IZA; 2016.

59. Statistics South Africa. Mid-year population estimates 2013. In: Statistical release P0302. Statistics South Africa: South Africa, 2013.

60. South African Audience Research Foundation. All media and products survey. South Africa; 2013. www.saarf.co.za

61. Republic of South Africa. National minimum wage act 2018. Pretoria Government Gazette; 2018.

62. Bourke EJ, Veerman JL. The potential impact of taxing sugar drinks on health inequality in Indonesia. BMJ Glob Health 2018;3.

63. Ganz ML, Wintfeld N, Li Q, et al. The association of body mass index with the risk of type 2 diabetes: a case-control study nested in an electronic health records system in the United States. Diabetol Metab Syndr 2014;6.
64. Ford ES, Williamson DF, Liu S. Weight change and diabetes incidence: findings from a national cohort of US adults. $A m ~ J$ Epidemiol 1997;146:214-22.

65. Shai I, Jiang R, Manson JE, et al. Ethnicity, obesity, and risk of type 2 diabetes in women: a 20-year follow-up study. Diabetes Care 2006;29:1585-90.

66. Resnick HE, Valsania P, Halter JB, et al. Relation of weight gain and weight loss on subsequent diabetes risk in overweight adults. $J$ Epidemiol Community Health 2000;54:596-602.

67. Guerrero-López CM, Unar-Munguía M, Colchero MA. Price elasticity of the demand for soft drinks, other sugar-sweetened beverages and energy dense food in Chile. BMC Public Health 2017; $17: 180$

68. Statistics South Africa. General household survey 2015. Pretoria: Statistics South Africa; 2015. 


\section{Correction: The distributional impact of taxing sugar- sweetened beverages: findings from an extended cost- effectiveness analysis in South Africa}

Saxena A, Stacey N, Puech PDR, et al. The distributional impact of taxing sugar-sweetened beverages: findings from an extended cost-effectiveness analysis in South Africa. BMJ Global Health 2019;4:e001317. doi: 10.1136/bmjgh-2018-001317

The published version misspelled co-author's name as Paula Del Ray Puech. The correct name should be Paula del Rey Puech.

Open access This is an open access article distributed in accordance with the Creative Commons Attribution Non Commercial (CC BY-NC 4.0) license, which permits others to distribute, remix, adapt, build upon this work non-commercially, and license their derivative works on different terms, provided the original work is properly cited, appropriate credit is given, any changes made indicated, and the use is non-commercial. See: http://creativecommons.org/licenses/by-nc/4.0/.

(C) Author(s) (or their employer(s)) 2019. Re-use permitted under CC BY-NC. No commercial re-use. See rights and permissions. Published by BMJ.

BMJ Global Health 2019;4:e001317corr1. doi:10.1136/bmjgh-2018-001317corr1

(A) Check for updates 